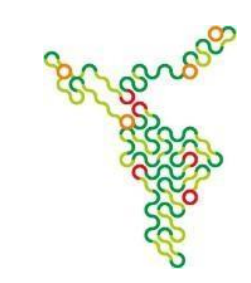

\title{
REDES SOCIAIS NA ESCOLA DO CAMPO À LUZ DE BAUMAN E DA MODERNIDADE LÍQUIDA: PERCURSOS E FRONTEIRAS
}

\author{
Maria Fatima Menegazzo Nicodem ${ }^{1}$ \\ Giordana Menegazzo da Silva² \\ Lucas Eduardo Menegazzo Nicodem ${ }^{3}$
}

\begin{abstract}
Resumo: Originado na pesquisa de pós-doutoramento «Muito além da calmaria: o ensino no campo, a modernidade líquida e as tecnologias contemporâneas de informação e comunicação» este trabalho tem como objeto as tecnologias da informação e da comunicação em seu uso didático numa instituição educacional do campo, a utilização da Internet permeada pelas redes sociais como estratégias de ensino impulsionadoras da aprendizagem. Teve como objetivo principal investigar o uso didático dessas tecnologias, propondo-Ihes a compreensão enquanto campo do conhecimento, mecanismos contemporâneos de transpor fronteiras, cujo espaço é teorizado pelos estudos culturais. Como respaldo teórico buscou-se saber sobre 0 uso dessas tecnologias contemporâneas como geradoras de um espaço de conhecimento configurado pelos estudos culturais e dimensionado pela «modernidade líquida» (conceituada por Bauman, 1999). Conclui-se, ao final desses estudos, a inexistência de obstáculos para o uso de tecnologias contemporâneas da informação e da comunicação na escola do campo, tanto quanto na escola urbana.
\end{abstract}

Palavras-Chave: Redes Sociais; Escola do Campo; Modernidade Líquida; Ensino; Bauman.

\section{SOCIAL NETWORKS IN COUNTRY SCHOOLS ACCORDING TO BAUMAN AND THE LIQUID MODERNITY: ROUTES AND BORDERS}

Astract: Originating from the postdoctoral research «Beyond the lull: education in the country, liquid modernity and contemporary technologies of information and communication» this study has as object the information and communication technologies in its didactic use, in an educational institution in the country, the use of Internet permeated by social networks as teaching strategies that drive learning. Its main objective was to investigate the didactic use of these technologies, proposing to them the understanding as a field of knowledge, contemporary mechanisms to cross borders, which space is theorized by cultural studies. As theoretical support, we sought to know about the use of these contemporary technologies as generators of a knowledge space configured by cultural studies and dimensioned by «liquid modernity» (conceptualized by Bauman, 1999). We concluded at the end of these studies, that there are no obstacles to

\footnotetext{
${ }^{1}$ UTFPR, Medianeira-PR, Brasil.

2 UNIOESTE, Marechal Cândido Rondom-PR, Brasil.

${ }^{3}$ UNIP, São Paulo-SP, Brasil.
} 


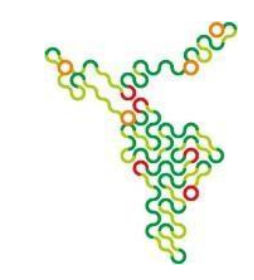

the use of contemporary information and communication technologies in rural schools, as well as in urban schools.

Keywords: Social networks; Country School; Liquid Modernity; Teaching; Bauman.

\section{REDES SOCIAIS, ESCOLA DO CAMPO E FRONTEIRAS: PRIMEIROS DIÁLOGOS}

Este trabalho se origina da pesquisa de pós-doutoramento da autora sob o título «Muito além da calmaria: o ensino no campo, a modernidade líquida e as tecnologias contemporâneas de informação e comunicação» e se baseia no foco observador da pesquisadora em suas andanças geográficas por várias instituições de ensino como docente formadora de professores, avaliando o exercício preparatório docente de alunos em preparação para a docência, especialmente da observação dos fazeres pedagógicos presentes em escolas do campo, no contato com os instrumentos da contemporaneidade, mormente a Internet, em seu caráter de tecnologia contemporânea da informação e da comunicação.

O objeto da pesquisa - as tecnologias contemporâneas da informação e da comunicação - foi pensado, em primeiro lugar, para investigar, observar, sentir e analisar como professores/as de uma instituição educacional do campo utilizam essas tecnologias representadas pela Internet que se deixa permear pelas redes sociais como estratégias de ensino instigadoras da aprendizagem de seus alunos, voltadas para os conteúdos de suas disciplinas.

Propôs-se com a pesquisa desenvolvida, a responder os seguintes objetivos: investigar o uso didático das tecnologias contemporâneas da informação e da comunicação em uma escola do campo, propondo a compreensão destas tecnologias enquanto campo do conhecimento, mecanismos contemporâneos de transpor fronteiras, cujo espaço é teorizado pelos estudos culturais; identificar, inventariar e analisar o uso didático das citadas tecnologias nos processos de ensino nessa escola do campo; dialogar sobre e compreender o uso dessas tecnologias contemporâneas enquanto instrumentos e/ou estratégias de ensino na escola do campo, como geradoras de um espaço de conhecimento configurado pelos estudos culturais e dimensionado pela «modernidade líquida» (conceituada por Bauman, 1999); enfocar essa «modernidade líquida» e a «vida líquida moderna», discorrendo sobre elas em seu caráter de 


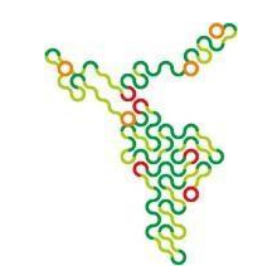

instrumentos inalienáveis e indispensáveis da contemporaneidade; explicar e apresentar essas tecnologias em sua constituição de artefatos da cultura e em seu papel de possíveis mediadoras dos processos de ensino; e, por final, destacar e relatar resultados que apontam percursos de produção de sentido para o conhecimento permeado por esses

objetos da cultura, quais sejam: a Internet, pela qual fluem as redes sociais e os blogs; afirmar, ainda, ao final dos presentes estudos, a inexistência de obstáculos para o uso de tecnologias contemporâneas da informação e da comunicação na escola do campo, tanto quanto na escola urbana.

No momento em que os estudos apontam para a escola do campo que se constituiu no locus da pesquisa aqui narrada, local em que, de forma avassaladora se dá conta da diluição das fronteiras com o espaço urbano, a discussão da práxis das tecnologias da informação e da comunicação, no interior da sala de aula ganha novas nuances. Isto significa dizer que o/a aluno/a da escola do campo é um leigo no uso das tecnologias? Ora, na contemporaneidade já não é mais possível se afirmar o desconhecimento das tecnologias pelos atores presentes na escola do campo, porque se entende que a diferença se encontra somente no endereço: uma escola se situa no espaço urbano a outra no campo e, na contemporaneidade, com acesso irrestrito às mesmas tecnologias, aos mesmos saberes, às mesmas posturas didáticas e ao mesmo nível de recepção. As fronteiras não se apresentam mais que nuances que historicizam os processos de esmaecimento das mesmas.

Sob este aspecto, as tecnologias já posicionadas entre os artefatos culturais da contemporaneidade, funcionam como objetos mediadores entre ensino e aprendizagem e apagadores de divisas.

O referencial teórico que constitui o presente relatório de pesquisa de estágio pós doutoral é proveniente dos Estudos Culturais e da vasta bibliografia de Zygmunt Bauman que circunda estudos e conceitos a respeito da vida e da modernidade líquidas, bem como da globalização, seus efeitos e transposição de fronteiras.

A investigação também destaca percursos de produção de sentidos para o conhecimento permeado pelas tecnologias contemporâneas da informação e da comunicação enquanto objetos da cultura. Assim, a Internet-mormente permeada pelas 


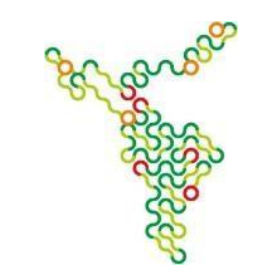

redes sociais - se constitui em base da pesquisa, gerando, por meio de um inquérito (questionário) com dez questões destinadas aos professores da escola do campo eleita, os dados primordiais analisados e discutidos nesta pesquisa, e, por conseguinte, os resultados delineados e apresentados na conclusão. Cabe pontuar que neste trabalho analisam-se a terceira e quarta questões, à luz dos ecos teóricos existentes no lastro bibliográfico já aqui proposto.

Eleita a escola estadual do campo para a presente pesquisa, por meio da contribuição e expectativas de seus/suas professores/as, elaborou-se um Projeto de Extensão com certificação da Universidade Tecnológica Federal do Paraná, instituição à qual se vincula profissionalmente a pesquisadora. O Projeto em questão, denominado «Tecnologias contemporâneas da informação e da comunicação nos processos de ensino na escola do campo» foi desenvolvido na forma de Oficinas, promovendo assuntos como «redes sociais nos processos de ensino e aprendizagem em sala de aula», intimamente relacionados ao tema da pesquisa.

Ainda que contemporaneamente, usar Internet - mais especificamente por meio das redes sociais - no ambiente educacional e para as práticas de ensino das diversas disciplinas da educação básica, ainda pode ser considerada atitude não-canônica. Apesar da pós-modernidade ter-se «abancado» na sociedade contemporânea, sob os mais diversos aspectos, de forma irreversível, a sala de aula tem andado a passos lentos, apresentando-se ainda distante das possibilidades didáticas possíveis e atuais como postagens em redes sociais em seu potencial pedagógico de parcialmente substituir o livro didático; e com estas mesmas redes sociais, por seu amplo poder de multiplicação de informações e de conhecimento.

Com as possibilidades didáticas presentes nas redes sociais é perceptível o motivo primordial da construção da hipótese desta pesquisa, qual seja, que na contemporaneidade já não é mais possível se afirmar o desconhecimento das tecnologias para a escola do campo, porque a diferença se encontra somente no endereço: uma escola se situa no terreno urbano e a outra no campo, com acesso às mesmas tecnologias, aos mesmos saberes, às mesmas posturas didáticas e o mesmo nível de recepção. A pesquisa foi realizada em 2016 no Colégio Estadual do Campo Maralúcia, Município de Medianeira, Estado Paraná, Brasil, por meio da realização de oficinas 


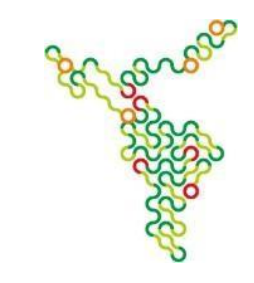

temáticas ministradas a Professores/as com aplicação do inquérito de relativa complexidade e semiestruturado a professores/as da citada instituição, recolheram-se os dados necessários.

A opção metodológica foi da pesquisa-ação, proposta que tem a premissa de que: fazer pesquisa-ação significa planejar, observar, agir e refletir de maneira mais consciente, mais sistemática e mais rigorosa o que fazemos na nossa experiência diária. Em geral, duas ideias definem um bom trabalho de pesquisa: - que se possa reivindicar que a metodologia utilizada esta adequada à situação, e - que se possa garantir de certa forma um acréscimo no conhecimento que existe sobre 0 assunto tratado. (RICHARDSON, 2010, p.68)

Nicodem (2013) aponta em sua pesquisa de doutorado o ponto de vista de Richardson (2010) sobre esta metodologia de pesquisa. Para este autor isso pode ser um bom ponto de partida para a pesquisa-ação, uma vez que, como o próprio nome dá indícios, a pesquisa-ação visa a produzir mudanças (ação) e compreensão (pesquisa).

Feitas as considerações metodológicas, retoma-se a introdução do trabalho, pontuando que a escola se apresenta cada vez mais mergulhada na cultura midiática. As tecnologias que propiciam a velocidade das idas e vindas da informação e da comunicação são realidade em todos os locais.

A sala de aula é o locus por excelência no qual as tecnologias contemporâneas ganham força didática pela intervenção docente. Aborda-se a inclusão digital, mas é preciso identificar a qual inclusão digital se faz referência. Entende-se essa inclusão não puramente pelo acesso, mas por quais caminhos ela chega e o que o conhecimento que vem por meio dela proporciona ao aluno.

«A cultura primeira do aluno é, desde já, uma cultura midiática, por força da sociedade em que vive» (Gadotti, 2005:23). O papel da escola, à luz deste contexto, seria fazer com que alunos - quer sejam crianças, quer sejam jovens ou adultos pudessem passar dessa cultura primeira à cultura elaborada. Sob este aspecto, este processo se constitui dialético, no qual uma não exclui a outra e sim, uma propicia a agregação de elementos à outra. Este movimento lhe concede completude. A cultura primeira é a que se adquire antes ou fora da escola, pela autoformação, não metódica e não sistemática, afirma Gadotti (2005).

Ao se focalizar a escola do campo que ora se constitui no locus que acolhe a presente pesquisa, a discussão da práxis das mídias tecnológicas da informação e da comunicação, no interior da sala de aula, ganha ainda novas nuances. Isto significa que 


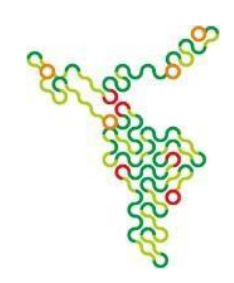

o aluno da escola do campo é um leigo no uso das tecnologias? Na contemporaneidade já não é mais possível se afirmar o desconhecimento das tecnologias para a escola do campo, porque a diferença se encontra somente no endereço: uma escola se situa na cidade e a outra no campo, com acesso às mesmas tecnologias, aos mesmos saberes, às mesmas posturas didáticas e o mesmo nível de recepção.

\section{DA MODERNIDADE LÍQUIDA, REDES SOCIAIS E QUEBRA DE FRONTEIRAS}

Protagoniza-se uma contemporaneidade povoada por fenômenos velozes nunca dantes vivenciados. As civilizações que nos antecederam tiveram tempo de degustar, deglutir e assimilar os fenômenos de seu tempo, de sua época e de sua cultura (ou de suas culturas) em movimentos lentos o suficiente para lhes permitir sentir saudades, repetir ações nos mesmos moldes e exemplificar às gerações seguintes o sucesso das ações do tempo em que as gerações mais antigas viviam. Não se rompiam fronteiras, nem barreiras com tamanha facilidade com que se o faz na contemporaneidade. Sob este aspecto, considera-se que:

As pressões voltadas à perfuração e à quebra de fronteiras, comumente chamadas de "globalização", fizeram seu trabalho; com poucas exceções, que estão desaparecendo rapidamente. Todas as sociedades são agora total e verdadeiramente abertas, seja material ou intelectualmente. Junte os dois tipos de «abertura» - a intelectual e a material - e verá por que toda injúria, privação relativa ou indolência planejada em qualquer lugar é coroada pelo insulto da injustiça: o sentimento de que o mal foi feito, um mal que exige ser reparado, mas que, em primeiro lugar, obriga as vítimas a vingarem seus infortúnios... (BAUMANN, 2007, p.12)

Sob a égide da imersão do mundo contemporâneo nas culturas - sim, «culturas» no plural - e no momento em que os estudos apontam para a escola do campo que se constituiu no locus da pesquisa da qual elegemos os dados da primeira questão para análise e discussão, os diálogos sobre a práxis das tecnologias da informação e da comunicação, no interior da sala de aula, ganham novas nuances. Isto significa dizer que o/a aluno/a da escola do campo é um leigo no uso das tecnologias? Ora, na contemporaneidade já não é mais possível se afirmar o desconhecimento das tecnologias pelos atores presentes na escola do campo, porque se entende que a diferença se encontra somente no endereço: uma escola se situa na cidade a outra no campo e, na contemporaneidade, com acesso irrestrito às mesmas tecnologias, aos mesmos saberes, às mesmas posturas didáticas e ao mesmo nível de recepção. 
Sob este aspecto, as tecnologias situadas em meio aos artefatos culturais da contemporaneidade, funcionam como objetos mediadores entre ensino e aprendizagem.

Significa que se está imerso na ausência de fronteiras e, portanto, rompe-se 0 antigo paradigma que focalizava uma «elite cultural». A contemporaneidade estabelece uma quebra da «hierarquia cultural» ou mesmo a eliminação desta nos moldes como era concebida sob o foco dos antigos signos. Desta forma, concebe-se estes antigos signos como:

frequência regular a óperas e concertos; entusiasmo, em qualquer momento dado, por aquilo que é visto como "grande arte»; hábito de torcer o nariz para «tudo que é comum, como uma canção popular ou um programa de TV voltado para o grande público». Isto não significa que não se possam encontrar pessoas consideradas (até por elas mesmas) integrantes da elite cultural, amantes da verdadeira arte, mais informadas que seus pares nem tão incultos assim quanto ao significado de cultura, quanto àquilo em que ela consiste (...) no que é desejável ou indesejável - para um homem ou mulher de cultura. (BAUMANN, 2013, p.7)

Os novos percursos de produção de sentido para cultura e os novos conceitos que a desconstroem e reconstroem, perpassando-se da vida e da modernidade líquidas, invadem a escola, ainda locus por excelência, do saber sistematizado, trazendo para dentro dos fazeres e saberes educacionais as tecnologias contemporâneas da informação e da comunicação enquanto objetos da cultura.

Desta forma, a Internet, permeada pela redes sociais, que ora se estuda e sobre a qual se dialoga, utilizadas como estratégias de ensino no interior dos procedimentos didáticos da escola do campo, podem ser, por si sós, consideradas símbolos dessa contemporaneidade que no momento se estende como uma densa nuvem sobre as sociedades como um todo, de forma quase universal - em maior ou menor grau - de forma benéfica ou até nefasta, em certos aspectos, como por exemplo àqueles que dizem respeito à privacidade (ou à falta dela) em dados contextos.

A despeito da lentidão com que os fenômenos eram vivenciados nas civilizações que nos antecederam, a civilização contemporânea vive fenômenos culturais que aparecem e se diluem, se liquefazem com uma velocidade sem precedentes, com uma fluidez até certo ponto assustadora. E esse fantasma da velocidade - uma vez transposto para o interior da escola - se constitui num fenômeno assustador, angustiante também, uma vez que muitos professores e professoras menos avisados ou aos quais não foi dado o tempo necessário para incorporar, paradoxalmente, a velocidade imposta pela 


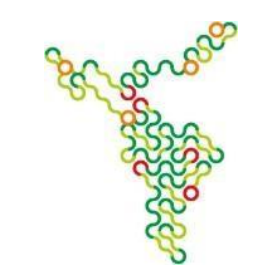

globalização, entram mesmo em pânico e no temor de «não dar conta» disto ou daquilo, de não vencer conteúdos, de não ser tão competente quanto o momento o exige, de não preparar adequadamente seu aluno para as exigências contemporâneas.

Em não raros casos, este conjunto de temores leva professores e professoras a psiquiatras e psicólogos - profissionais tão desavisados quanto o/a professor/a sobre as síndromes contemporâneas, tão despreparados quanto os primeiros. O que dirão eles aos primeiros? Dar-lhes- ão pílulas que diminuem a loucura e a ansiedade? Sim, mas elas - a loucura e a ansiedade - não são integralmente internas ao ser humano. São provindas em parte dos fenômenos externos que montam e desmontam paradigmas numa velocidade assustadora e, com essa mesma velocidade, colocam os seres humanos numa mímesis que até eles próprios desconhecem viver.

« «grau de abertura» da sociedade aberta ganhou um novo brilho, jamais
imaginado por Karl Popper, que cunhou o termo. Tal como antes, o termo se
refere a uma sociedade que admite francamente sua própria incompletude, e,
portanto, é ansiosa em atender suas própria
possibilidades ainda não-intuídas, muito menos exploradas. Mas significa, além
disso, uma sociedade impotente, como nunc antes, em decidir o próprio curso
com algum grau de certeza e em proteger o itinerário escolhido, uma vez
selecionado. (BAUMANN, 2007, p.13)

Posta, ainda que de forma velada, a presença da ansiedade na escola e na civilização da contemporaneidade, cabe abordar as redes visíveis e invisíveis que compõem o cotidiano dessa instituição. Ainda que contemporaneamente, usar Internet pela qual passam as redes sociais no ambiente educacional e para as práticas de ensino das diversas disciplinas da educação básica, ainda pode ser considerada atitude meramente alternativa, tamanha a falta de tempo que os educadores tiveram de internalizá-la e incorporá-la a suas ações didáticas.

Apesar da pós-modernidade ter-se instalado na sociedade contemporânea, sob os mais diversos aspectos, de forma irreversível, a sala de aula tem andado a passos lentos - especialmente pela velocidade sobre a qual discorremos até o momento.

Por estes aspectos, apresenta-se ainda distante das possibilidades didáticas possíveis e atuais como os blogs, por exemplo, em seu potencial pedagógico poderiam substituir o livro didático; como as redes sociais, com seu amplo poder de multiplicação de informações e de conhecimento, podem agregar-se às ações e relações que permeiam a sala de aula e «brincam» de entrar e sair da escola, entrar e sair do campo, 


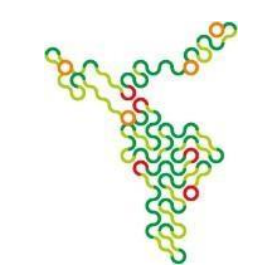

entrar e sair da cidade. Já não há fronteiras. E se aparecem, são tão tênues que sequer são percebidas.

Com somente estas duas possibilidades didáticas - os blogs e as redes sociais é perceptível o motivo primordial da pesquisa, qual seja: «Na contemporaneidade já não é mais possível se afirmar

o desconhecimento das tecnologias para a escola do campo, porque a diferença se encontra somente no endereço: uma escola se situa na cidade e a outra no campo, com acesso às mesmas tecnologias, aos mesmos saberes, às mesmas posturas didáticas e o mesmo nível de recepção».

A escola se apresenta cada vez mais mergulhada na cultura midiática. As tecnologias que propiciam a velocidade das idas e vindas da informação e da comunicação são realidade em todos os locais. A sala de aula é o locus por excelência no qual as tecnologias contemporâneas ganham força didática pela intervenção docente.

Aborda-se a inclusão digital, mas é preciso identificar a qual inclusão digital se faz referência. Entende-se essa inclusão não puramente pelo acesso, mas por quais caminhos ela chega e o que o conhecimento que vem por meio dela proporciona ao aluno.

Ao se apontar para a escola do campo que ora se constitui no locus pesquisado, a discussão da práxis das mídias tecnológicas da informação e da comunicação, no interior da sala de aula, ganha ainda novas nuances. Isto significa que o aluno da escola do campo é um leigo no uso das tecnologias?

Na contemporaneidade já não é mais possível se afirmar o desconhecimento das tecnologias para a escola do campo, porque a diferença se encontra somente no endereço: uma escola se situa no espaço geográfico urbano e a outra no espaço geográfico do campo, com acesso às mesmas tecnologias, aos mesmos saberes, às mesmas posturas didáticas e a níveis parecidos de recepção.

\section{DISCUSSÕES, ALTERNATIVAS, ÂNSIAS E PONDERAÇÕES: FRONTEIRAS DILUÍDAS E REDES SOCIAIS}

Esta seção, ao apresentar os resultados questão a questão, os discute deixandoos permearem- se por Bauman, especialmente pelas reflexões que averbam ao contexto a Modernidade Líquida e seus fenômenos. A análise é realizada pela ordem em que as 
questões aparecem no questionário, de forma progressiva e relacionando - quando o caso - uma questão à outra ou até uma alternativa à outra.

Antes da análise e discussão dos dados, mostra-se o perfil dos/as professores/as que aceitaram participar da pesquisa. O Quadro 1 apresenta a faixa etária dos mesmos.

\begin{tabular}{|c|c|}
\hline Faixa Etária & Quantidade de Professores/as nesta faixa \\
\hline 21 a 30 anos & 3 \\
\hline 31 a 40 anos & 6 \\
\hline 41 a 50 anos & 3 \\
\hline Mais de 50 anos & 6 \\
\hline
\end{tabular}

Quadro 1. - Faixa Etária dos/as Professores/as participantes da pesquisa.

\begin{tabular}{|c|c|}
\hline Tempo de docência & Quantidade de Professores/as nesta condição \\
\hline Até 10 anos & 3 \\
\hline 11 a 15 anos & 1 \\
\hline 16 a 20 anos & 6 \\
\hline Mais de 20 anos & 9 \\
\hline
\end{tabular}

Quadro 2 - Tempo de docência

Cada uma das duas questões analisadas são apresentadas nos quadros seguintes e os dados respectivos estudados à luz dos estudos teóricos; as mesmas por si só - demandam estudos e considerações dadas as diferentes quantificações.

\section{QUESTÃO 1: O PAPEL DO PROFESSOR ANTES DO ADVENTO DAS TECNOLOGIAS CONTEMPORÂNEAS}

A terceira questão do questionário assim se enuncia: «Quanto ao papel daquele professor que atuava em sala de aula antes do advento das mídias e tecnologias que se utilizam hoje nos processos de ensino e de aprendizagem» o Quadro 31 apresenta os dados que são analisados na sequência.

\begin{tabular}{|c|c|c|c|c|c|c|c|}
\hline & $\begin{array}{c}\text { Alternativ } \\
\mathbf{a}\end{array}$ & 0 & 1 & 2 & 3 & 4 & 5 \\
\hline & $\begin{array}{r}\text { a) Era considerado detentor exclusivo do conhecimento e, por isso, } \\
\text { usava sua } \\
\text { autoridade de conhecedor único para o exercício do poder em algum } \\
\text { nivel. }\end{array}$ & 3 & & 2 & 6 & 2 & 6 \\
\hline b) & $\begin{array}{l}\text { Exercia um papel de caçador de conteúdos encerrados em } \\
\text { enciclopédias para, sistematizados no quadro de giz, fazer o } \\
\text { repasse aos alunos. }\end{array}$ & 2 & 1 & 1 & 6 & 3 & 6 \\
\hline $\begin{array}{l}\text { c) } \\
\text { no }\end{array}$ & $\begin{array}{l}\text { Era um transmissor, um multiplicador de conteúdos que se perpetuavam } \\
\text { tempo, cristalizados e ensinados sempre da mesma forma. }\end{array}$ & 2 & 1 & 6 & 1 & 3 & 6 \\
\hline d) & $\begin{array}{l}\text { O de promover uma formação puramente moral e intelectual, } \\
\text { lapidando o aluno para a convivência social, tendo como } \\
\text { pressuposto a conservação da } \\
\text { sociedade em seu estado atual (status quo) }\end{array}$ & & 1 & 2 & 6 & 2 & 8 \\
\hline
\end{tabular}



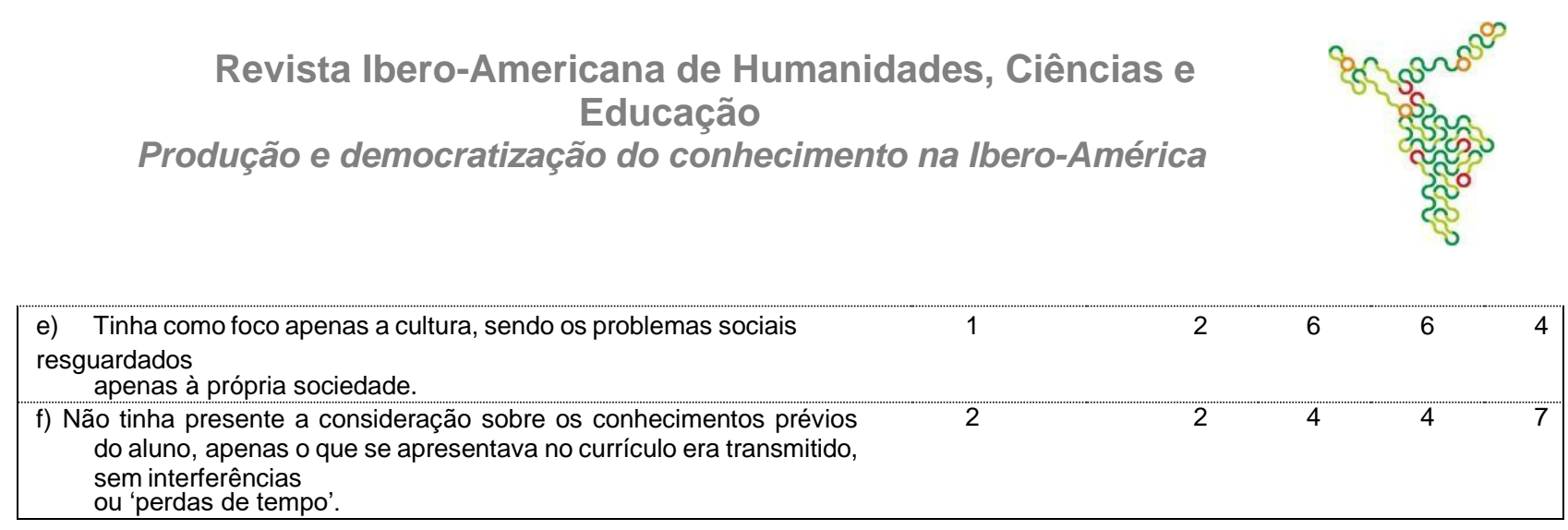

Quadro 3 - Respostas dos Professores/as às alternativas da Questão nº3

Para a alternativa «a» sobre o pensamento dos/as professores ao enunciado da questão que reflete sobre o papel daquele professor que atuava em sala de aula antes do advento das mídias e tecnologias das quais se utilizam hoje nos processos de ensino e de aprendizagem, ao responderem a alternativa em questão - que o professor «Era considerado detentor exclusivo do conhecimento e, por isso, usava sua autoridade de conhecedor único para o exercício do poder em algum nível», dos 19 professores/as participantes da pesquisa, há uma diversidade de pensamento a respeito, sendo que 03 $(15,8 \%)$ deles aponta que esta alternativa nada representa no contexto do pensamento dos professores que já atuavam em sala de aula; 14 (73,7\%) se encontram nas faixas que veem esta forma de pensar como regularmente representativa, representativa e muito representativa.

Há que se entender, seguindo Orofino (2005), que estes processos se iniciam a partir da mediação individual que se efetiva nas trocas pessoais e intersubjetivas.

(...) a escola já é um local de mediações. Só que, de fato, a escola subestima esta condição e deixa este papel social relegado ao espontaneísmo do dia-a-dia, sem potencializar sua condição de mediadora e sem assumir a responsabilidade sobre isto. (...) Várias escolas já adotam iniciativas de uso dos meios no contexto pedagógico e para que isto aconteça, não existem fórmulas e receitas prontas. O que é necessário, isto sim, é a abertura e vontade política de experimentar e também de correr os eventuais riscos que se revelem ao longo dos processos de criação de novos caminhos. (OROFINO, 2005, p.65-66).

A alternativa remete, desta forma, a uma análise sobre a construção da identidade docente ante a cultura que se arremessa ao centro da escola, protagonizando o que Bauman (2013) compreende como «multiculturalismo" ao qual concebe como a resposta mais frequente das classes instruídas e influentes quando se pergunta que valores cultivar e que direção seguir em nossa era de incerteza. O autor eleva essa resposta ao status de cânone e, além disso, a transforma em um axioma que não exige fundamentação nem prova.

A alternativa «b» à questão do papel do professor antes das mídias e que o 


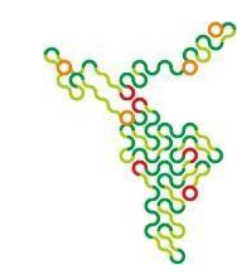

apresenta como um possível professor que exercia um papel de caçador de conteúdos encerrados em enciclopédias para, sistematizados no quadro de giz, fazer o repasse aos alunos, 15 (778,9\%) desses/as professores/as pontuam suas respostas entre considerar esta questão como regularmente representativa, representativa e muito representativa. Isto significa que, de alguma forma, veem o professor pré-midiático como refém das enciclopédias, de conteúdos clássicos e limitados.

Era um/a professor/a à mercê de uma «monolinguagem» - aquela única presente nas bibliotecas e com as quais (e minguadas) deveria fazer malabarismos para fazer veicular os conhecimentos até seu aluno. Em tempos de multimídias, «linguagens híbridas, textos, imagens e sons» (Orofino, 2005:67), todos andando juntos dentro da sala de aula, considera-se o pensamento de Moran (1993) paraquem:

a escola desvaloriza a imagem e toma as linguagens audiovisuais como negativas para o conhecimento. Ignora a televisão, o vídeo; exige somente 0 desenvolvimento da escrita e do raciocínio lógico. (...) Não se trata de opor os meios de comunicação, mas de integrá-los, de aproximá-los para a educação seja um processo completo, rico, estimulante. (MORAN, 1993, p.3)

Na mesma perspectiva deste autor, (Orofino, 2005) propõe que há três códigos de significação presentes na mídia e, no caso da questão em análise - nas redes sociais: texto, imagem e som. Afirma que estamos tão acostumados com a linguagem televisual que se torna comum compreendê-la como um conjunto de construções «naturais», que obedecem a determinados padrões de «normalidade» discursiva. É necessário estar atentos para a diferença entre aquilo que é «normal” e aquilo que é hegemônico, dominante.

No que se refere à alternativa «c $c$ » de que o professor que atuava anteriormente às tecnologias contemporâneas era um transmissor, um multiplicador de conteúdos que se perpetuavam no tempo, cristalizados e ensinados sempre da mesma forma.

Dos/as professores/as que responderam à pesquisa, $6(31,6 \%)$ veem baixa representatividade nesta afirmação, enquanto 9 (47,3\%) veem como regularmente representativa, representativa e muito representativa. Há uma expressiva variação nas opiniões colhidas sobre esta alternativa. Esta oscilação representa uma escola ante os desafios da contemporaneidade. O que era no passado e o que é no presente essa escola? 
Aquino (2012) afirma que perscrutar analiticamente a atualidade educacional e, por conseguinte, a multiplicidade de sentidos que a caracteriza, constitui um empreendimento pontilhado de riscos. E assevera ainda que

\begin{abstract}
o maior desses riscos é de ceder à tentação, de todo ilusória, de descrever o presente com tintas naturalistas, esquecendo-se que os fenômenos aí presentes têm origem e destinação inexoravelmente incertas, bem como de que a faculdade de divisar o imprevisto que a época nos oferece dá-se, na maioria das vezes, apenas por meio de enquadres interpretativos saturados. (AQUINO, 2012, p.137)
\end{abstract}

Ao mesmo tempo que os/as professores/as participantes da pesquisa afirmam categoricamente que os conteúdos pré tecnologias eram perpetuados no tempo sempre pela mesma cartilha, cristalizados, congelados e ensinados com a mesma metodologia, também se interpõem - eles/elas mesmos/as, professores/as, no presente - tendo participado desse passado em que se viam em meio a este congelamento de conteúdos e metodologias, transpostos para o presente com as múltiplas possibilidades e oportunidades que Ihes são oferecidas na escola da contemporaneidade, independente ser esta da cidade ou do campo.

Segundo Aquino (2012), se, por um lado, as paredes translúcidas que delimitam o campo de visão do observador externo não permitem apreciar o fato de que, para aquelas existências ali encerradas, as águas do tempo são sempre turvas, conquanto escassas e, por isso, gélidas, por outro lado, essas mesmas paredes não conseguem evitar que alguns saltem suicidamente para fora desse cenário e se sujeitem a concebêlo em sua insólita, artificial e melancólica exuberância.

Aponta ele que a contemporaneidade significa angariar uma distância estratégica em relação ao passado e mesmo ao presente - especialmente afastar-se da aparente luminosidade dos discursos da moda, acolhendo a porção de sombra que lhe é imanente, de modo a ser capaz de operar pequenas rachaduras, discretos curtos circuitos e perceber o presente sem tantos choques em relação ao passado. Sobre a alternativa «d» que vê o professor do passado com o papel de promover uma formação puramente moral e intelectual, lapidando o aluno para a convivência social, tendo como pressuposto a conservação da sociedade em seu estado atual (status quo), 16 (84,2\%) acreditam nesta afirmação, tendo apontado a mesma como regularmente representativa, representativa 
e muito representativa. Se, por um lado, observa-se esta expressiva quantidade de respostas que formulam uma ideia de um professor do passado, «portador de viseiras", busca-se em Bauman (2013) que não se deve presumir que o valor de uma proposição depende de quem a formulou, com base na sua experiência, nem que se tem o monopólio da descoberta da melhor solução. Isso não significa, aponta este autor, que é necessário aceitar todas as proposições como igualmente válidas e dignas de escolha.

De forma inevitável, algumas serão melhores que outras. Significa apenas que admitimos nossa inaptidão para dar opiniões absolutas ou formular sentenças definitivas. Concordamos que a utilidade e o valor verdadeiros de proposições concorrentes só podem ser estabelecidas no curso de um multidiálogo, no qual todas as vozes sejam admitidas e em que todas as comparações e justaposições possíveis sejam feitas de boa-fé e com boas intenções. (BAUMAN, 2013, p.59).

Se aquele professor anterior às tecnologias contemporâneas tinha os movimentos limitados no tocante à própria ação docente, também se considera com Bauman (2013) o reconhecimento da diferença cultural, para a finalidade deste argumento, é o início, e não o fim da questão. Concebe-se neste contexto comparativo entre passado e presente se constitua em um processo político, quiçá, útil e até benéfico - num processo que vale à pena empreender.

A alternativa «e» que contempla o professor que atuava anteriormente às tecnologias da atualidade, - como aquele que tinha como foco apenas a cultura, sendo os problemas sociais resguardados apenas à própria sociedade - tem em Orofino (2005) o aporte quando se faz a análise de políticas de significação e ideologias:

Esta autora afirma que diante das várias correntes teórico-metodológicas que se 'debruçaram' sobre este assunto, destaca-se também a contribuição dos estudos culturais ingleses e a importância que o conceito de ideologia recebe em suas teorizações.

Teorias da ideologia, mesmo que difiram entre si, aceitam como básico a capacidade da sociedade de criar e sustentar uma forma de cultura dominante e de auto interesse, gerando apresentações e imagens, ideias e valores, que disfarçam as realidades da existência social. (HALL, 1994, p.88).

Isto seria equivalente ao pensamento de Bauman (2007, p.93) para quem a tendência em direção a uma comunidade da semelhança é um sinal de retração não puramente no que diz respeito à alteridade externa, mas também em relação ao compromisso com a interação interna que, segundo ele é animada, mas turbulenta, 
revigorante, mas incômoda. A atração de uma comunidade da mesmice é a de «uma apólice de seguro contra os riscos que povoam a vida diária num mundo polivocal».

Por final, a imersão nessa mesmice não diminui e nem afasta, aponta Bauman (2013), os riscos que a incitaram. Como todo paliativo, pode no máximo prometer um refúgio em relação a alguns de seus efeitos mais imediatos e temidos.

Ao analisar como os/as professores/as pontuaram a alternativa «f» e como sentem um possível professor anterior às tecnologias como aquele que «não tinha presente a consideração sobre os conhecimentos prévios do aluno, apenas o que se apresentava no currículo era transmitido, sem interferências ou perdas de tempo» 15 (78,9\%) deles/as compreendem que sim, que certamente esse professor, em boa parte de suas atitudes, agia de forma meramente focada em cumprir o conteúdo.

Sousa (2016) indica que se voltarmos os olhos para o passado, na busca de um sentido profundo que a profissão docente encerra, percebe-se que a figura do professor foi ganhando, ao longo dos tempos, atribuições diversas, por vezes, antagônicas, raramente compreendidas pelo docente. Eis o que se apresenta nas nuances dessa alternativa.

\footnotetext{
Em quadros temporais mais fechados, a sua missão manteve-se sobretudo centrada no domínio do conteúdo, geralmente pouco acessível à generalidade da população. Poucos eram os eleitos a quem ele, sábio-expert, fazia o favor de conceder a matéria, como se de uma dádiva se tratasse, para, por sua vez, esses mesmos eleitos a devolverem o mais fiel e exatamente possível. Os exercícios de reprodução e repetição, com forte apelo à memorização, e que à primeira vista nos parecem inócuos, trazem, no entanto, consigo, uma concepção de um mundo organizado de determinada forma, onde as verdades são eternas e absolutas. (SOUSA, 2016, p.1)
}

Isto significa que, antes da avalanche tecnológica que se derramou no interior da escola, o professor vivia uma espécie de terror ou angústia em dar conta de conteúdos emanados de enciclopédias, bibliotecas físicas e livros didáticos. O que se percebe (mas deixaremos esta discussão para outra oportunidade) é que este terror ou angústia alterou sua origem, encontrando-se, na contemporaneidade, no excesso de conteúdos advindos, especialmente, da web. Gera uma espécie de contramão entre o que era e o que se tornou.

De tempos sólidos, nos quais havia a segurança enciclopédica que transformava o professor no detentor do conhecimento, a tempos líquidos, nos quais o professor se transformou - ou deveria ter se transformado - no mediador entre o conhecimento e o aluno, por meio da sistematização didática.

Bauman (2007) traz a reflexão por um viés que apresenta o mundo sem medos, o mundo perfeito e o mundo líquido - a propósito, cabem bem na reflexão que ora se 


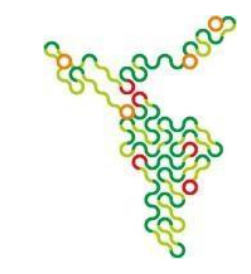

delineia.

Quando sir Thomas More desenhou a sua planta de um mundo livre das ameaças imprevisíveis, o improviso e a experimentação, cheios de riscos e erros, estavam se tornando rapidamente a ordem do dia. Sir Thomas sabia muito bem que, tanto quanto um projeto para o estabelecimento de uma vida boa, seu plano de um mundo limpo da insegurança e dos medos sem fundamento era apenas um sonho: ele chamou sua concepção de "utopia", referindo-se ao mesmo tempo a duas palavras gregas: eutopia, ou seja, «lugar bom», e outopia, que significa «em lugar nenhum". (BAUMAN, 2007, p.100)

Sob este aspecto é possível apresentar-se o professor do passado, cujas didáticas previam tudo com segurança, sem sustos, sem atropelos e sem medos, ao passo que o do presente vive aos sobressaltos e, em muitos casos, devido às mazelas da própria formação, está lá um professor vivendo de sobressaltos e procurando provar ou outorgar sua autoridade pela força de argumentos nem sempre honestos. Liquidez, para Bauman (2007), «tempos líquidos».

\section{QUADRO 1: O PAPEL DO PROFESSOR APÓS O ADVENTO DAS TECNOLOGIAS CONTEMPORÂNEAS}

A questão apresenta o seguinte enunciado: «Quanto ao papel daquele professor que atua em sala de aula após o advento das mídias e tecnologias contemporâneas». O Quadro 4 apresenta os dados que são analisados na sequência.

\begin{tabular}{|c|c|c|c|c|c|c|c|}
\hline & Alternativa & 0 & 1 & 2 & 3 & 4 & 5 \\
\hline a) & $\begin{array}{l}\text { Tem o papel de educador associado a uma sequência de } \\
\text { responsabilidades, entre elas a de ser mediador do conhecimento } \\
\text { formal. }\end{array}$ & 1 & 1 & & 1 & 4 & 12 \\
\hline b) & $\begin{array}{l}\text { Alguns elementos passam a ser básicos para o educador pós- } \\
\text { moderno. Um deles é a curiosidade. Percebendo o mundo e o } \\
\text { pensamento como } \\
\text { inacabados o homem deve estar sempre em busca das respostas para } \\
\text { suas perguntas. (Lívia Chamusca, 2011) }\end{array}$ & & & 2 & 1 & 5 & 11 \\
\hline & $\begin{array}{l}\text { educador assume o papel de pesquisador e incorpora a criticidade. } \\
\text { A sociedade contemporânea exige que o professor assuma uma } \\
\text { posição crítica dentro da sociedade, ou seja, venha a perceber-se } \\
\text { como elemento constituinte desta e responsável pela sua mudança } \\
\text { para melhor. (Lívia } \\
\text { Chamusca, 2011) }\end{array}$ & & & 1 & 1 & 6 & 11 \\
\hline & $\begin{array}{l}\text { criatividade é um dos fatores que permeia o trabalho do professor } \\
\text { contemporâneo. Por meio desta característica, desenvolve seu } \\
\text { potencial inventivo, sugerindo atividades dinâmicas, motivando seus } \\
\text { alunos a participarem dos trabalhos propostos, usando as } \\
\text { tecnologias } \\
\text { contemporâneas da informação e comunicação. }\end{array}$ & & & & 3 & 6 & 10 \\
\hline & $\begin{array}{l}\text { professor contemporâneo tem humildade suficiente para admitir os } \\
\text { seus erros e procurar consertá-los ao longo do caminho, mudando a } \\
\text { sua prática para melhor. Se o professor se coloca sempre como o } \\
\text { dono da verdade, não } \\
\text { lhe é possível seguir em busca da mudança. }\end{array}$ & & & & 5 & 5 & 9 \\
\hline & $\begin{array}{l}\text { professor da atualidade deve estar envolvido com seu aluno no } \\
\text { âmbito social, uma vez que cada sujeito vem da sociedade e volta } \\
\text { para ela. Desta forma, tem o compromisso de educa-lo para } \\
\text { reconhecer a própria importância como sujeito e protagonista da } \\
\text { história individual e coletiva e } \\
\text { sua importância na transformação do mundo. }\end{array}$ & & & & 1 & 5 & 13 \\
\hline
\end{tabular}

Quadro 4 - Respostas dos Professores/as às alternativas da Questão n 04

Revista Ibero-Americana de Humanidades, Ciências e Educação. Criciúma, v. 6.n.3, 2020.

ISSN - 2675-3375 
Apresentada a tabela com a quantificação das respostas dadas à questão, passase à análise:

Para a alternativa «a» da questão «quanto ao papel daquele professor que atua em sala de aula após o advento das mídias e tecnologias contemporâneas, este professor tem o papel de educador associado a uma sequência de responsabilidades, entre elas a de ser mediador do conhecimento formal», 17 (89,5\%) pontua a alternativa como regularmente representativa, representativa e muito representativa, o que traduz que os/as professores/as participantes da pesquisa se identificam com este professor mediador presente nos anais da contemporaneidade.

As fronteiras já não são tão intensamente marcadas e, quando existem, aparecem com nuances que confundem dois ou mais mundos, ou campos de conhecimento, ou formas de arte, ou formas de ensinar, ou formas de aprender, ou, ou, ou...

\begin{abstract}
Ainda não está nada claro se apenas as fronteiras específicas, até hoje reconhecidas e consagradas, são as vítimas destacadas do atual levante semiótico; ou se a turbulência de agora pressagia uma revisão total dos padrões de práxis do passado. (...) Se essa chance de materializar a cultura humana assistirá a uma revolução jamais vista no passado, de vez que o único aspecto dela até agora nunca questionado - e que invariavelmente emergiu vitorioso e intacto das águas profundas de tumultos e agitações revolucionárias - é a estrutura da práxis humana. (BAUMAN, 2012, p.277)
\end{abstract}

Seria um caso para os estudos da recepção? - e mais: da recepção dos fenômenos contemporâneos dentro da escola? Já não se enxergam as hierarquizações. Como propõe Orofino (2005), a proposta metodológica estava suficientemente estruturada, porém aberta aos imponderáveis do percurso e às novidades ao longo do caminho. Ante a multiplicidade de estímulos, materiais, informações, conhecimentos advindos pela rede invisível e materializando-se diante dos olhos de professores/as e de alunos/as no interior da escola, há que se ver como uma proposta viável fazer um trabalho de parceria inter e multidisciplinar para se entender o turbilhão que vem rolando por essa rede. E num esforço metodológico almejar o conhecimento sistematizado.

Há um professor que diz «presente» e aceita ser mediador. E «voilà» o conhecimento com ponte (o professor) para o aluno.

Sobre a alternativa «b» para o professor pós mídias de que «alguns elementos passam a ser básicos para o educador pós-moderno. Um deles é a curiosidade. Percebendo o mundo e o pensamento como inacabados o homem deve estar sempre em busca das respostas para suas perguntas"

Pontuada com $17(89,5 \%)$ dos/as professores/as como regularmente representativa, representativa e muito representativa, considera-se Orofino (2005) para perceber um olhar criterioso e orientado por uma perspectiva plural e atenta à significação, tanto na forma, quanto no conteúdo, verificando como são representadas múltiplas posições de sujeito que emerge dentro da escola e de dentro dela.

Sobre esta curiosidade tão bem ponderada pelos/as professores/as, cabe perceber que

os processos de ensino-aprendizagem, todos nós cabemos, se tornam muito mais ricos quando estão ancorados na experiência, no contexto do mundo vivido, possibilitando que: 


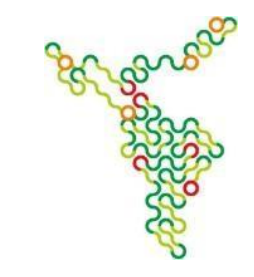

ação e reflexão, juntas, em uma permanente relação da teoria com a prática, construam o conhecimento. Portanto, mais do que esperar fórmulas prontas, uma pedagogia dos meios na escola requer que os educadores arrisquem, sugiram e criem as possibilidades de ação a partir de suas experiências. No terreno do novo, do ainda inexplorado, é experimentando que se pode aprender, em processo, construindo os caminhos sempre em parceria com os estudantes e a comunidade escolar mais ampla. (OROFINO, 2005, p.133)

A curiosidade que transborda da sala de aula é elemento crucial para as descobertas da ciência

- isto é ponto pacífico - porque sem curiosidade não há efetivamente ciência. A curiosidade sistematizada leva bem estar à sociedade. É ela também que impulsiona e gera intercâmbios de conhecimentos em todos os níveis, em todos os espaços e entre classes sociais. Bauman (2012) aponta para um intercâmbio transcultural; ou ainda, difusão cultural. Segundo ele, a difusão, antes um evento perturbador na vida cotidiana das culturas, agora se tornou o modo de existência do dia a dia.

Para pontuarem a alternativa $" \mathrm{C} »-« \mathrm{O}$ educador assume o papel de pesquisador e incorporaa criticidade. A sociedade contemporânea exige que o professor assuma uma posição crítica dentro da sociedade, ou seja, venha a perceber-se como elemento constituinte desta e responsável pela sua mudança para melhor». - obteve-se 18 $(94,7 \%)$ dos/as professore/as afirmando esta alternativa ser regularmente representativa, representativa e muito representativa. Seria utopia a presença de um professor crítico no âmbito da escola?

Bauman (2007) afirma que:

para os jardineiros, a utopia era o fim da estrada; para os caçadores, é a própria estrada. Os jardineiros visualizavam o fim da estrada como a justificativa e o triunfo da utopia. Para os caçadores, o fim da estrada só pode ser o final da utopia vivida, a ignominiosa derrota. (Bauman, 2007:113)

Ora, uma utopia que vem no bojo da criticidade docente, está mais para a ideia dos jardineiros do que dos caçadores, uma vez que um professor crítico, "cavocador» de respostas, fomentador de discussões, produção de ideias e atitudes, é aquele que insufla de esperanças a escola.

Um professor crítico não surge por encanto, não advém do nada, não se faz ao acaso. É resultado do próprio esforço, no entanto, incentivado e cristalizado na trajetória de sua formação. Sobre isto, Alarcão (2001) propõe um professor circundado pela ação:

Acreditar na possibilidade de mudança como resultado do esforço contínuo, cientifico, ético, solidário, coletivo e persistente que se processa em um movimento iniciado na reflexão feita sobre as ações efetivadas na espessura concreta do cotidiano e, dialeticamente, a ele retorna com maior qualidade e mais consistência, voltando com vigor epistemológico e com força coletiva para provocar rupturas e (re) construir. (ALARCÃO, 2001, p.80)

É no diálogo que surge no interior da escola e que se estende para o exterior da escola, que o professor se efetiva como um protagonista e construtor da história, em sua prática social de mediar o conhecimento que vêm aos borbotões pelas redes e mídias contemporâneas, sistematizando-o, organizando-o, dando-o a entender ao aluno, dialogando com este e impulsionando-o a prosseguir com este movimento de mediação - agora e, por sua vez, como ele mesmo - aluno - um protagonista da própria história, 
no meio onde vive e se desloca.

A alternativa «d» - «a criatividade é um dos fatores que permeia o trabalho do professor contemporâneo. Por meio desta característica, desenvolve seu potencial inventivo, sugerindo atividades dinâmicas, motivando seus alunos a participarem dos trabalhos propostos, usando as tecnologias contemporâneas da informação e comunicação». - posiciona o professor numa posição confortável - a da liberdade de criação. Esta questão foi pontuada por $19(100 \%)$ dos/as professores/as participantes da pesquisa como regularmente representativa, representativa e muito representativa.

Não há dúvida sobre que é a novidade o ingrediente que dá o primeiro impulso à consciência criativa.

uma produção criativa não pode ser simplesmente uma resposta nova. Ela deve igualmente ser adaptada, ou seja, deve satisfazer diferentes dificuldades ligadas às situações nas quais se encontram as pessoas. Sujeitos como os avaliadores mencionam geralmente esse duplo aspecto de novidade e de adaptação quando os interrogamos sobre suas concepções de criatividade. (LUBART, 2007, p.16)

A criatividade docente - numa perspectiva angariada pelos estudos de Bauman (2013) - passa pela luta por reconhecimento. Para ele, a luta por reconhecimento, quando comprimida para se adequar ao arcabouço da autoderminação e da autorrealização culturais, revela seu potencial antagônico. $O$ autor não se perde nas minúcias da discussão:

(...) e como mostra a experiência recente, genocida, em última instância. Quando situadas na problemática da justiça social, contudo, as demandas por reconhecimento e as ações políticas delas consequentes tornam-se um catalisador de encontros, diálogos e negociações que podem (embora não necessariamente) levar à integração de uma ordem superior - ampliando, não ocultando, o espectro da comunidade ética. (Bauman, 2013, p.87)

Sendo a criatividade um dos elementos presentes no cotidiano docente, acompanhando o professor em sua ação didática, considera-se Torrance (2002) estudioso da criatividade no mundo educacional. Para ele a criatividade pode ser conceituada como um processo que torna alguém sensível aos problemas, deficiências, hiatos ou lacunas nos conhecimentos, e «o leva a identificar dificuldades, procurar soluções, fazer especulações ou formular hipóteses, testar e retestar essas hipóteses, possivelmente modificando-as, e a comunicar os resultados". (Torrance, 2002:54)

E então, $19(100 \%)$ dos/as professores/as participantes consideraram regularmente representativa (5), representativa (5) e muito representativa (9) para a alternativa «e» que vê o professor pós advento das mídias como um professor contemporâneo que tem humildade suficiente para admitir seus erros e procurar consertá-los ao longo do caminho, mudando sua prática para melhor. Se o professor se apresenta sempre como dono da verdade, não Ihe e possível seguir em busca de mudança. Sendo assim, rompe-se com o professor do passado que se posicionava como «dono da verdade", detentor único do conhecimento e, a propósito desta postura, fazia e afirmava inúmeras bobagens e sandices àquele aluno em posição sedenta de aprender. Por muito tempo se perpetuou esta postura de arrogância. Os novos tempos fizeram os/as professores/as alterarem esta ótica da ação docente. A maioria deles já se ocupa de uma nova postura docente que preconiza a humildade de admitir que não sabe tudo, a decência de pensar junto com o próprio aluno alguns novos conhecimentos, a ética de ir em busca de saberes que ele ainda não domina e, sobretudo, a postura de «ser» junto com seu aluno, numa tendência crescente à humanização e não-perpetuação de 


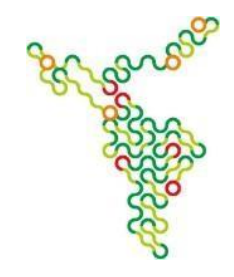

procedimentos de ensino mecânicos e excessivamente conteudista e angustiados para dar conta do currículo, sem prestar atenção aos diferentes ritmos dos alunos.

A alternativa «f» - «o professor da atualidade deve estar envolvido com seu aluno no âmbito social, uma vez que cada sujeito vem da sociedade e volta para ela. Desta forma, tem o compromisso de educá-lo para reconhecer a própria importância como sujeito e protagonista da história individual e coletiva e sua importância na transformação do mundo». - obteve, como nas duas alternativas anteriores 19 (100\%) dos/as respondentes pontuando-a como regularmente representativa, representativa e muito representativa. E se olharmos pontualmente para esta alternativa, vemos nela um vínculo expressivo com a alternativa anterior.

O professor anterior às tecnologias contemporâneas da informação e da comunicação alocava- se em um espaço estabelecido para a «guerra do reconhecimento» - afinal, se assumisse não saber algo, beiraria as valas do vexatório. Sobre esta guerra Bauman (2013) assim se expressa:

\begin{abstract}
Há óbvias razões (...) pelas quais a lógica das «guerras de reconhecimento» leva os lados beligerantes a transformar a diferença num valor absoluto. Cada apelo por reconhecimento contém, afinal, o elemento de uma tendência fundamentalista difícil de suavizar, e mais ainda de eliminar, que em geral empresta às demandas (...) um "caráter sectário». Formular a questão do reconhecimento no contexto da justiça social, e não no da «autorrealização» (...) pode ter efeitos benéficos nesse domínio. (BAUMAN, 2013, p.86)
\end{abstract}

Sob este aspecto o reconhecimento docente, do ponto de vista contemporâneo, pressupõe o alargamento de vínculos. Isto significa que a um/a professor/a que se propõe a ser o mediado entre o conhecimento e o aluno, é também proporcionada a oportunidade de aprender também. $E$ isto se dá no próprio ato/movimento de ensinar mediando e de mediar ensinando.

\title{
Finalizando o percurso pela dissolução das fronteiras pelas Redes Sociais
}

As perspectivas dos docentes vindas à tona não somente nas questões transpostas para este artigo, mas na íntegra da pesquisa, nos apontam que a cultura da pós modernidade, ou contemporaneidade, é uma cultura da modernidade líquida, que envolve todos os espaços didáticos. Isto inclui a escola do campo, locus de nosso trabalho.

Ao «convocar-se» Bauman (2012) que pressupunha a existência de um fenômeno objetivo chamado "cultura», aponta-se para o pensamento do mesmo que analisa esse fenômeno em função do notório «retardo do conhecimento» e o analisa como algo que talvez tenha sido desvelado com atraso. Sob este aspecto, segundo ele, é gerada uma espécie de paradoxo, ao se verificar que a desconstrução do conceito de cultura tenha acabado por vir na onda da «culturalização» das ciências sociais. De fronte a este panorama, a «cultura» não precisava mais mascarar sua própria fragilidade humana e desculpar-se pela contingência de suas escolhas. «A naturalização da cultura foi parte e parcela do moderno desencantamento do mundo» (Bauman, 2012:11)

Em análise ampla, o temor trazido à tona pelas respostas dos/as professores/as em mergulhar nesse conceito de «cultura» ressignificado pela pós modernidade, nada mais é que um reflexo interno

- e também perverso - da velocidade com que as mudanças tecnológicas chegaram à escola. Em Bauman (2012) é nitidamente perceptível este fenômeno, 


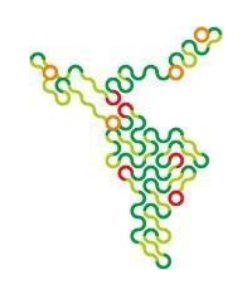

afirmando e reafirmando que o ritmo acelerado da mudança revela a temporalidade de todos os arranjos mundanos. Ora, a temporalidade é uma característica atemorizadora da existência humana. Para tanto, afirma que «a liberdade de

autodeterminação é uma benção - e uma maldição», dado que, juntas, trazem em seu bojo o paradoxo da ação para um ou para outro lado - da negação ou da afirmação, em análise circunstancial.

Desta forma, podemos mesmo considerar que o fim em aberto das tecnologias, impulsionadas pela sedução de seu uso, entram numa certa vertente da cultura, qual seja, a partir de Bauman (2012), aquela homogênea e coesa, uma cultura de uma sociedade que se altera vagarosamente, assim como a coesão de qualquer cultura é obtida pela recriação com sucesso, no processo inicial de treinamento, do mesmo tipo de personalidade básico. Sendo assim, «coesão e homogeneidade» se constituem em sinônimos de mudança de ritmo vagaroso. Eis que também aparece um conceito de «cultura» que se pode entender como um conjunto de «processos selecionados historicamente criados» que direcionam a reação humana e os estímulos internos e externos, ajustando-se às duas exigências.

Dado que a educação é um dos veículos da cultura e, ao mesmo tempo, um dos fortes elementos dessa cultura, considerada como o maior mecanismo de transformação social, a sedução proporcionada pelas tecnologias da informação e da comunicação em sala de aula, coloca a Internet como forte aliada do professor para a disseminação dos saberes, para a sua argumentação e exemplificação, ultrapassando os muros da escola e fazendo ir e vir para dentro dela, por meio das redes sociais, os conhecimentos que se interseccionam de dentro para fora e de fora para dentro.

Ao se entender como os/as professores/as percebem a importância das mídias e tecnologias contemporâneas nos processos de ensino e de aprendizagem na escola do campo, percebemos que eles entendem os diversos aspectos da tecnologia, vendo nela «a função da cultura presente no uso das mídias e tecnologias da informação, como aquela que deve satisfazer as necessidades de conhecimento e informação existentes, criando e recriando novos desafios» (Resposta de Professor à pesquisa).

Em «tempos líquido-modernos» compreendemos com Bauman (2013) que a cultura e sua esfera artística que se direciona à responsabilidade individual, tem sua função em garantir que a escolha seja e continue a ser uma necessidade e um dever inevitável da vida, enquanto a responsabilidade pela escolha e suas consequências permaneçam no local no qual foram situadas pela condição humana líquido-moderna: sobre os ombros do sujeito que agora é designado ou conceituado para a posição de líder da própria «política de vida».

Diante disso, é ponto pacífico que a cultura cumpre seu papel de ora estreitar, ora alargar os laços com a sala de aula. Estes movimento de estreitamento e alargamento estão presentes no número de docentes que quantifica essa cultura das tecnologias em sala de aula como muito representativa. Muito embora não se trate especificamente de mudança ou modificação de paradigma, Bauman (2013) aponta para uma era "pósparadigmática" na história da cultura (e não apenas da cultura em si). E ainda mais, embora o termo "paradigma" ainda não tenha desaparecido do vocabulário cotidiano, ele juntou-se àquilo que Bauman (2013) define como família das "categorias zumbis".

Assim sendo, a modernidade líquida, no lastro do uso das tecnologias em sala de aula, é a arena de uma batalha constante e mortal travada contra todo tipo de paradigma 


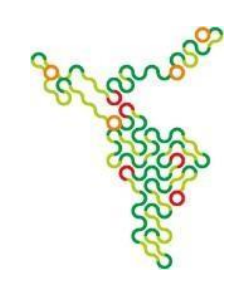

- e, na verdade, como entende Bauman (2013), contra todos os dispositivos homeostáticos que servem ao conformismo e à rotina, ou seja, que impõem a monotonia e mantêm a previsibilidade.

Sobre os aspectos, na opinião dos docentes, que apontam que as tecnologias para os processos de ensino e aprendizagem tem como principal preocupação evitar o sentimento de insatisfação e que isso desperta uma sede constante de busca do novo, do desconhecido, do não conhecido, do mais distante, de mais conhecimento, muitos dos/as professores/as responderam que este movimento das tecnologias em sala de aula é representativo. Segundo Brito e Purificação (2011), isto pode ser configurado como o fato de que as tecnologias educacionais apresentam uma característica específica, qual seja, aquela em que, com frequência, o aluno tem muito mais domínio sobre a tecnologia do que seu professor e a manipula sem medo e sem restrições. Esse ponto exige do professor «(...) uma mudança de postura em sala de aula, em que a interação com seus alunos passará a ser uma atitude necessária para o bom andamento do seu trabalho pedagógico». (Brito; Purificação, 2011:83)

O trabalho pedagógico, mediado pelo uso das redes sociais - mecanismos da contemporaneidade trazidos pelas tecnologias da informação e da comunicação, apresenta questões sobre o que são as mediações. Diante destas, Orofino (2005) assevera a proposição de identificar aqueles percursos de produção de sentido como

ponto de partida e consumo cultural, aos quais define como apropriação e recusa ou resistência, considerados como estruturantes, configurando e reconfigurando tanto a interação com os meios, «como a criação do sentido desta interação» (Orozco, 1993:46).

Ao analisar a importância das mídias sob o aspecto apresentado pelos contornos dos novos cenários culturais que não se dissolvem na escuridão do crepúsculo dos tempos, mesclando o passado ao presente e o presente ao futuro, muitos dos/as professores/as sentem esta afirmação como representativa e muito representativa. Há um movimento de intensa produção de sentido na relação pontuada entre cenários culturais e tecnologias contemporâneas presentes na escola. Sobre isto, procura-se abranger processos de movimento do significado de um texto para outro, de um discurso para outro, de um evento a outro.

Em Silverstone (1999), no sentido de que a mediação implica a constante transformação de significados, tanto em pequena, quanto em grande escala, significante e insignificante, na medida em que os textos midiáticos e os textos sobre a mídia circulem em suas formas escritas, discursiva e audiovisual, e enquanto nós, individual e coletivamente, direta e indiretamente, contribuamos para a sua produção.

Neste sentido, Orofino (2005) inclui a escola em sua qualidade de cenário social em que se efetiva esta circulação de significados e sentidos produzidos pelas e sobre as mídias. Ao se levar o debate sobre o uso das mídias, na forma de pesquisa para dentro da escola e, neste caso, da escola do campo, destaca-se um ponto de partida - conhecer um pouco mais sobre as teorias da mídia e da comunicação a fim de que estas ofereçam algum suporte reflexivo para as ações no espaço escolar. É então que se aponta para Martin-Barbero (1997) e para Orozco (1993) no enfoque da teoria das mediações.

Martin-Barbero (1997), apontando para as teorias críticas da mídia e da comunicação social contemporâneas percebe um nível de consenso na definição das mesmas pelo ponto de vista integral dos processos de circulação e produção de sentidos. Estes estudos, segundo Orofino (2005) também de lançam ao desafio de identificar, 


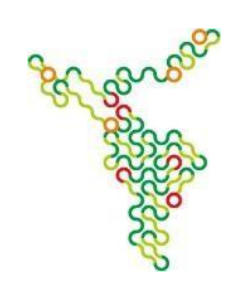

conceituar, mapear as operações e os modos de reconhecimento entre produtoresmeios-receptores em um movimento dialético e sócio histórico.

Sobre a percepção da importância das mídias sob o foco da facilidade dos movimentos das tecnologias contemporâneas da informação e da comunicação que as coloca como facilitadora de fluxos e espaços, vários professores participantes da pesquisa imprimiram sua impressão de representativa e muito representativa para este aspecto. Sobre esta escolha, aponta-se para contornos estruturais que encetam para mudanças culturais. Estas conduzem a um debate interno específico que

apresenta os meios de comunicação contemporâneos em sua expansão exponencial, bem como o desenvolvimento científico e tecnológico. Sob a análise histórica, Orofino (2005) aponta para a própria Internet, que em seu início, foi desenvolvida para fins de controle militar e de inteligência. Posteriormente foi disponibilizada para a sociedade civil. E nesse desenvolvimento - primeiro utilizada para fins comerciais - nas duas últimas décadas adentra os espaços da escola e, por isso, já transpõem os muros da sala de aula e a dimensão histórica é superada pelos estudos demandados pela didática de seu uso como estratégia em sala de aula, no ensino das diversas disciplinas da educação básica.

Orofino (2005) argumenta a ressignificação do mundo, as brechas, os espaços e as negociações de sentido. Aponta, sob este aspecto, que as novas teorias latinoamericanas que focam para a relação entre comunicação e cultura têm sido muito criativas na medida em que buscam transpor estas dificuldades relativas à herança multidisciplinar e fragmentária dos estudos da mídia. As mídias nos conduzem para uma abordagem que enfoca a complexidade dos processos de comunicação social, justamente a partir do conceito de mediações.

O conceito de mediação migra para a escola, definindo-se como mediação escolar. Se a escola é local de conexão entre muitas culturas que advém tanto de identidades, quanto de diferenças socioculturais, então é preciso buscar sobrepor todas as mediações que se apresentam a partir do cenário escolar. Neste se entrelaçam as mediações. Orofino (2005) chama a atenção para a mediação institucional, porque afinal, a escola é uma instituição social das mais rígidas e estruturadas ao longo da história. Não é a única, no entanto, dado que as múltiplas possibilidades de negociações de sentido nem sempre aparecem da esfera institucional e, sim, da situacional e individual.

Sobre a percepção das mídias e tecnologias na aprendizagem na escola do campo, que visualiza o mundo sem fronteiras e que usa as tecnologias da informação e da comunicação para movimentar saberes e fazê-los chegar instantaneamente a qualquer lugar, os/as professores/as concebem que a escola já é um local de mediações. Esta é a análise desta valoração proposta por esses professores. Embora ainda em muitas circunstâncias a escola ainda subestime esta condição de mediação, abandonando este papel social ao espontaneísmo cotidiano, não potencializando como deveria sua condição mediadora e sem assumir sua responsabilidade, a escola corre o risco de se transformar em um espaço inexpressivo quando se trata do acionamento das mediações. Usar blogs

e redes sociais como estratégias ricas de potencial para o ensino de conteúdos das disciplinas, também potencializa o papel da escola frente à comunidade em que está inserida.

Em tempos de modernidade líquida em que todos os fenômenos da vida humana, 


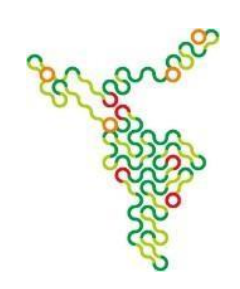

segundo Bauman (2012), parecem ser socioculturais, a rede de dependência dos artefatos da cultura passa pela escola, entra e sai dela pelas veias fluidas da tecnologia invisível feita de satélites e fibras óticas aquém dos olhares humanos. Desta forma, amparados nessa concepção, endossamos-lhe o pensamento de que a permanência da transitoriedade; a durabilidade do provisório são fatos presentes em nossa vida contemporânea. E seguimos a perspectiva do mesmo de que a determinação objetiva irrefletida na consequência subjetiva das ações; o papel social perpetuamente subdefinido, ou, mais corretamente, a inserção no fluxo vital sem a âncora de um papel social - tudo isso, juntamente com as características correlatas da vida líquido-moderna, foi exposto e documentado em várias épocas, na trajetória histórica.

Para finalizar e, seguindo Aquino (2012), apontamos que perscrutar analiticamente a atualidade educacional e, por conseguinte, a multiplicidade de sentidos que a caracteriza, constitui- se num empreendimento pontilhado de riscos. $E$ asseveramos que o maior desses riscos é de ceder à tentação, de todo ilusória, de descrever o presente com tintas naturalistas, esquecendo-se que os fenômenos aí presentes têm origem e destinação inexoravelmente incertas.

$\mathrm{E}$ assim, a faculdade de divisar o imprevisto que a época nos oferece dá-se, na maioria das vezes, apenas por meio de enquadres interpretativos saturados. De tempos sólidos, nos quais havia a segurança enciclopédica que transformava o professor no detentor do conhecimento, a tempos líquidos, nos quais o professor se transformou - ou deveria ter se transformado - no mediador entre o conhecimento e o aluno, por meio da sistematização didática.

Sob este aspecto é possível apresentar-se o professor do passado, cujas didáticas previam tudo com segurança, sem sustos, sem atropelos e sem medos. Ao passo que o do presente vive aos sobressaltos e, em muitos casos, devido às mazelas da própria formação, está lá um professor vivendo de sobressaltos e procurando provar ou outorgar sua autoridade pela força de argumentos nem sempre honestos. Liquidez. Para Bauman (2007), «tempos líquidos».

\section{Referências}

AQUINO, Júlio Groppa. Do cotidiano escolar: ensaios sobre a ética e seus avessos.

São Paulo. Summus, 2012

BAUMAN, Zygmunt. A cultura no mundo líquido moderno. Tradução Carlos Alberto Medeiros, 1.ed., Rio de Janeiro: Zahal, 2013.

. Modernidade Líquida. Tradução Plínio Dentzien, Rio de Janeiro: Zahar, 1999.

. Tempos Líquidos. Tradução Carlos Alberto Medeiros, Rio de Janeiro:

Zahar, 2007. 
Revista Ibero-Americana de Humanidades, Ciências e Educação

Produção e democratização do conhecimento na Ibero-América

Bordoni, Carlo. Estado de Crise. Tradução Renato Aguiar, Rio de Janeiro: Zahar, 2016.

OROFINO, Maria Isabel. Mídias e mediação escolar: pedagogia dos meios, Participação e visibilidade. São Paulo: Cortez / Instituto Paulo Freire, 2005. 